\title{
ZONEAMENTOS DA VULNERABILIDADE AMBIENTAL E EXPECTATIVA DE PERDA DE SOLO: É POSSÍVEL USAR A USLE NA DETERMINAÇÃO DE VULNERABILIDADE AMBIENTAL?
}

\author{
ENVIRONMENTAL VULNERABILITY ZONING AND SOIL LOSS EXPECTANCY: IS IT \\ POSSIBLE TO USE USLE FOR THE DETERMINATION OF ENVIRONMENTAL \\ VULNERABILITY?
}

\author{
Alessandra Ribeiro de SOUZA ${ }^{1}$; Francisco Antonio DUPAS ${ }^{1,2}$; Isabela Neves \\ DRUMMOND $^{3}$; Carlos Wilmer COSTA ${ }^{4,5}$ \\ ${ }^{1}$ Programa de Pós-Graduação em Engenharia de Energia - Universidade Federal de Itajubá. Avenida B P S, 1303 - Pinheirinho, \\ Itajubá - MG. E-mail: alessandra.ribeirods@gmail.com \\ ${ }^{2}$ Programa de Pós-Graduação em Ciências Ambientais - Universidade Federal de São Carlos. Rodovia Washington Luiz, s/n, São \\ Carlos - SP. E-mail: dupas_unifei@ hotmail.com \\ ${ }^{3}$ Instituto de Matemática e Computação - Universidade Federal de Itajubá. E-mail: isadrummond@ unifei.edu.br \\ ${ }^{4}$ Programa de Pós-Graduação em Engenharia Sanitária e Ambiental - Universidade Federal do Rio Grande do Norte. Avenida \\ Senador Salgado Filho, 3000 - Candelária, Natal - RN. E-mail: carloswilmercosta@ gmail.com \\ ${ }^{5}$ Geologia de Planejamento do Meio Físico - Universidade Federal de São Carlos. Rodovia Washington Luiz, s/n, São Carlos - SP.

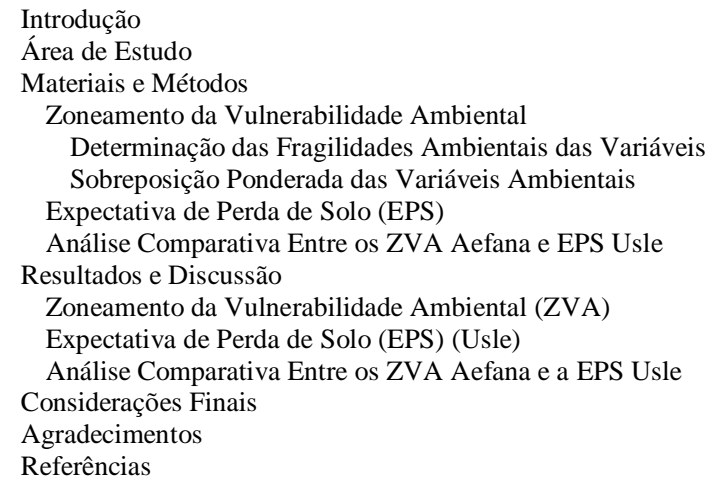

RESUMO - Para garantir a sustentabilidade das práticas de uso do solo, os métodos de zoneamento da vulnerabilidade ambiental (ZVA) são essenciais na ocupação de áreas em bacias hidrográficas. Nesse sentido, utilizando como área de estudo a bacia hidrográfica do Ribeirão do Feijão (BHRF), São Carlos-SP (Brasil), os ZVA obtidos pelo método da Análise Empírica da Fragilidade dos Ambientes Naturais e Antropizados (AEFANA), apoiado em índices de dissecação do relevo e classes de declividades, foram comparados com a expectativa de perda de solo (EPS) resultante da Equação Universal de Perda de Solo (USLE). Esta comparação visa identificar a possibilidade de usar a USLE como mais um método para determinação do ZVA em bacias. Os dados foram processados em Sistema de Informações Geográficas e comparados por meio de acertos por matriz de confusão em classes de estabilidade. Os resultados demonstram uma baixa coincidência entre os modelos AEFANA e USLE, porém, a maior influência da topografia em conjunto com as atividades antrópicas permitiu à USLE a determinação de fragilidades não indiciadas pelo ZVA da AEFANA, especialmente nas cabeceiras dos rios. A predição de erosão hídrica pela USLE como modelo para ZVA poderá auxiliar o planejamento territorial da BHRF quando integrada a AEFANA.

Palavras-chave: Zoneamento da vulnerabilidade ambiental, Fragilidade ambiental, Perda de solo, USLE, Planejamento de bacias hidrográficas.

\begin{abstract}
In order to ensure the sustaintability of land use practices, enviornomental vulnerability zoning (EVZ) methods are crucial in the occupation of sites in watersheds. Therefore, using as study area the Feijão River Watershed (FRW), São Carlos-SP (Brazil), the EVZ obtained by the Analysis of Natural and Anthropogenic Environmental Fragility (ANAEF) method, with support of the relief dissection index and slopes classes, were compared to the soil loss expectancy (SLE) obtained by the Universal Soil Loss Equation (USLE). This comparison aimed to identify the possibility of using USLE as another method to determine EZV in watersheds. The data were processed in Geographic Information Systems and compared by correct classification rates measured by the confusion matrix for stability classes. The results indicated little coincidence between ANAEF and USLE models, however, the greater influence of the topography associated with anthropogenic activities allowed the USLE to determine fragilities sites not indicated by the ANAEF EVZ method, especially in the headwaters areas. The prediction of water erosion by USLE as a model for EZV could help territorial planning when integrated with ANAEF.

Keywords: Environmental vulnerability zoning, Environmental fragility, Soil loss, USLE, Watersheds planning.
\end{abstract}

\section{INTRODUÇÃO}

Os seres humanos constantemente locais intensamente explorados por atividades transformam o ar, solo e água ao seu redor em econômicas (Aretano et al., 2013; Grecchi al., 
2014). A desordenada expansão urbana e agropecuária e a consequente intensificação de processos erosivos do solo, por outro lado, estão associadas com a degradação tanto da quantidade quanto da qualidade de recursos hídricos em bacias hidrográficas (Costa et al., 2018; 2019).

A oferta de água, por sua vez, influencia diretamente os atendimentos dos múltiplos usos da agropecuária, da demanda de abastecimento de água potável a baixo custo e da geração de energia (Stolton et al., 2008).

Desse modo, o manejo adequado do solo amplia a capacidade agropecuária e minimiza danos ambientais como assoreamento, turbidez e poluição em mananciais e hidrelétricas (Cunha et al., 2011; Mukundan et al., 2013; FernándezGetino \& Duarte, 2015).

Diante desse cenário, a gestão de bacias hidrográficas visando a proteção dos recursos hídricos por meio da conservação da vegetação torna-se um desafio. Uma das maneiras existentes de apoio ao processo de planejamento e gestão ambiental ocorre através da implementação de instrumentos como o conhecimento das fragilidades ambientais, uma vez que visam o estabelecimento de princípios de uso do solo em função das características intrínsecas dos ecossistemas (Nijs et al., 2004; Conway \& Lathrop, 2005; Nguyen et al., 2016). A modelagem de fragilidades, mapeada em Sistema de Informações Geográficas (SIG), proporciona uma importante ferramenta base ao planejamento integrado de ações de prevenção e mitigação de danos em áreas identificadas sob diferentes níveis de sensibilidade ambiental e pressão antrópica (Conway \& Lathrop, 2005; Manfré et al., 2013).

Assim, os modelos de ZVA, como a AEFANA (Spörl \& Ross, 2004; Liu et al., 2017), possibilitam analisar e comparar os efeitos potenciais na natureza e na paisagem de acordo com as tendências da sociedade, gerando informações úteis e multitemporais em direção ao planejamento territorial, em especial para uso em políticas públicas (Aretano et al., 2015; Zou et al., 2017), como os sistemas de pagamento por serviços ambientais com manejo florestal (Nijs et al., 2004; Machado \& Dupas, 2013; Machado et al., 2014).

O modelo AEFANA, proposto por Ross (1994), está fundamentado em Tricart (1977), que define as unidades ambientais como unidades ecodinâmicas estáveis e instáveis conforme seus níveis de alteração antrópica. Nesse modelo, os mapas de ZVA (Ruhoff et al., 2005) são obtidos a partir da aplicação do Processo Analítico Hierárquico (AHP) como operador de inferência espacial para a integração dos dados (Saaty, 2008), podendo ser alicerçados por dois diferentes modelos que consideram parâmetros comuns de pluviosidade, geologia, cobertura do solo e pedologia, enquanto se diferenciam pela utilização de outra variável (geomorfologia ou declividade) na análise (Cunha et al., 2011; Dai et al., 2012).

De maneira a auxiliar na modelagem do ZVA, a busca de validação de metodologias de EPS, como a USLE (Wischmeier \& Smith, 1978), amplia as opções para o estudo de estratégias hierárquicas específicas de conservação de áreas através da identificação das classes de vulnerabilidade as quais necessitam serem protegidas ou recuperadas (Liu et al., 2007; Aretano et al., 2015).

A USLE permite contextualizar cenários de uso e manejo do solo e da aplicação de práticas conservacionistas, estimando a perda média anual de solo em função do produto de fatores de erosividade, erodibilidade, topografia, cultivo e manejo do solo e práticas conservacionistas (Kinnell, 2010; Oliveira et al., 2011; Karamage et al., 2016). Portanto, determina as áreas passíveis de erosão e simula ação dos principais fatores de influência nas PS.

Para a validação entre o ZVA originário do AEFANA em relação a USLE, é necessária a determinação da exatidão dos dados utilizando métodos que comparem os resultados obtidos, sendo a matriz de confusão uma das formas comumente empregadas para avaliar a taxa de acerto de um sistema de classificação.

Neste método, o processo usual que gera uma estimativa de acerto de um classificador utiliza elementos conhecidos, que compõem o que se chama de conjunto verdade.

O sistema de classificação é treinado usando parte dos dados, e em seguida, as regras geradas são testadas no restante do conjunto, comparando o resultado com a verdade do problema.

$\mathrm{O}$ número de pontos (neste caso, pixels) correta e incorretamente classificados são colocados numa matriz onde é possível verificar a classe à qual pertence o elemento no conjunto verdade e a classe à qual pertence o elemento a partir do resultado da classificação (Duda et al., 2000; Kuncheva, 2004). Nesse sentido, o 
presente estudo objetiva verificar a possibilidade de se utilizar o modelo de EPS da USLE como mais uma alternativa para determinação da fragilidade ambiental, utilizando como modelos de validação os ZVA obtidos pela aplicação da AEFANA apoiados nos índices de dissecação de relevo e nas classes de declividades. O procedimento foi testado no manancial urbano da BHRF, São Carlos (SP), através do uso da matriz de confusão. Procurou-se, através das respostas, auxiliar no entendimento das relações entre os modelos e suas variáveis permitindo, com a ampliação do aparato técnico, identificar novas maneiras de otimização do ZVA.

\section{ÁREA DE ESTUDO}

A BHRF tem aproximadamente $222,4 \mathrm{~km}^{2}$ e localiza-se na região sudeste do Brasil, área central do Estado de São Paulo (Figura 1), sendo considerada o manancial mais importante para o município de São Carlos, cuja população em 2010 era de 221.692 habitantes (SEADE, 2010). Em 2006, a cobertura de terra e usos econômicos na bacia eram representados principalmente por pastagem $(38,7 \%)$, citricultura por laranja $(13,9 \%)$, reflorestamento de eucalipto e pinus $(10,2 \%)$ e cana-de-açúcar $(3,1 \%)$, bem como por fragmentos florestais $(16,4 \%)$, solos expostos $(12,8 \%)$ e superfície impermeabilizada (4,9\%) (Cunha et al., 2011).

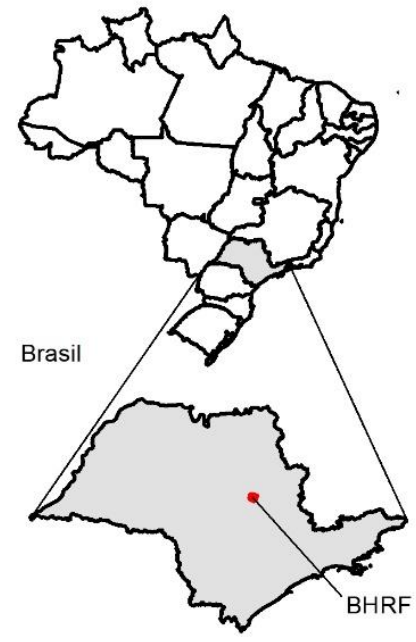

Estado de São Paulo

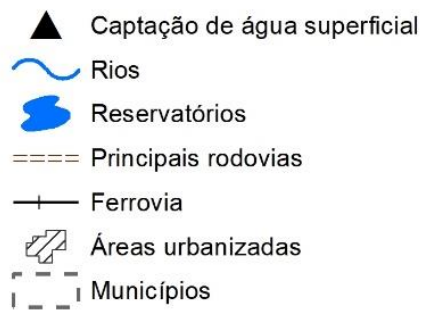

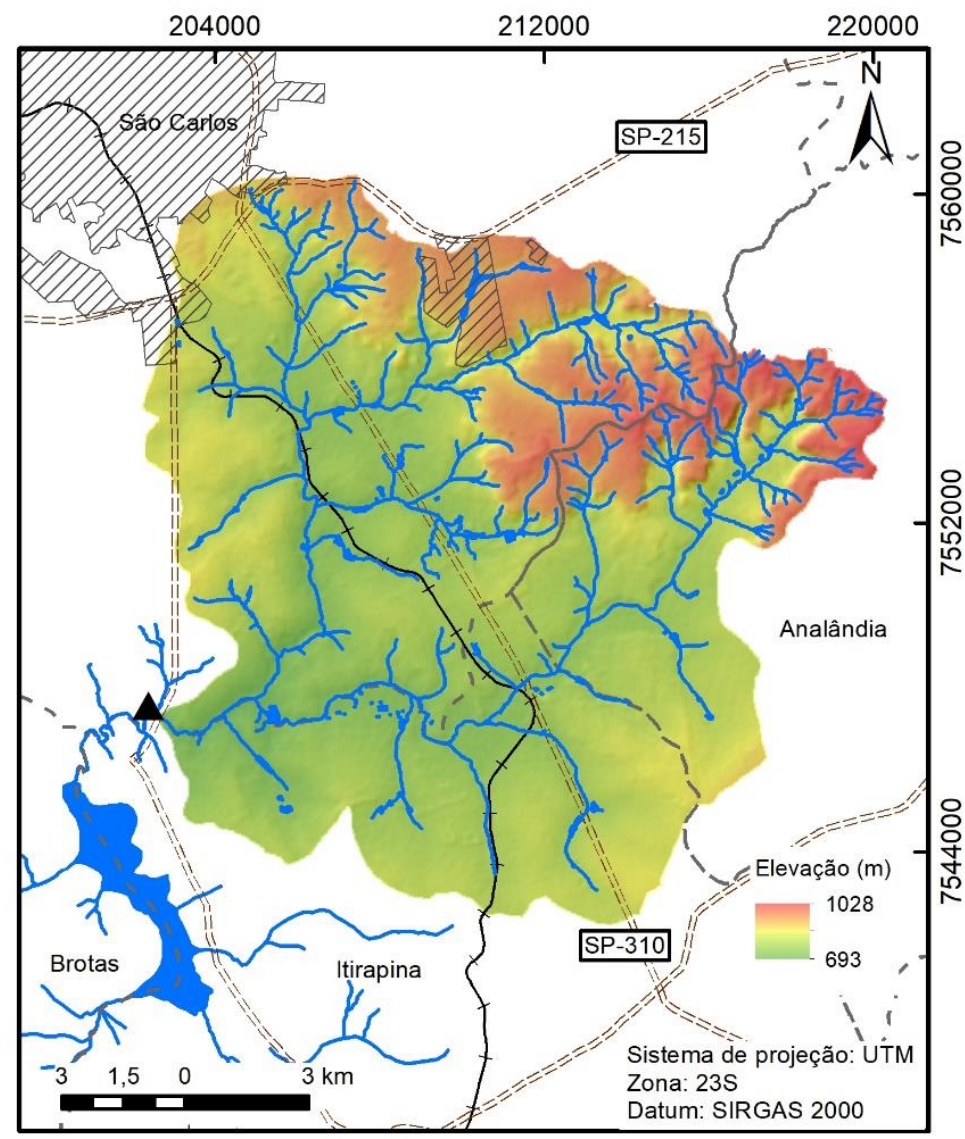

Figura 1 - Localização do município, mancha urbana e captação superficial do manancial de São Carlos na BHRF, drenagens e municípios do entorno (adaptado de Costa et al., 2018).

Os fragmentos florestais são compostos por florestas semidecídua, ripariana, cerradão e cerrado.

O tipo climático é o Cwa, de acordo com a classificação de Köppen, $\operatorname{com} 22^{\circ} \mathrm{C}$ de temperatura média no mês mais quente (CEPAGRI, 2018). A média anual de pluviosidade é acima de $1.400 \mathrm{~mm}$ e a umidade relativa do ar apresenta uma média anual acima de $65 \%$. O relevo de transição entre o
Planalto Ocidental e as Cuestas apresenta altitudes que variam de $775 \mathrm{~m}$ a $1.020 \mathrm{~m}$ (Gonçalves, 1986). $\mathrm{Na} \mathrm{BHRF}$, o fundo dos vales dos rios do planalto e áreas a leste e oeste são ocupados por rochas eruptivas da Formação Serra Geral que cobrem aproximadamente $90 \%$ da Formação Botucatu em toda sua extensão e comporta-se como corpos impermeáveis de residual argiloso com coeficientes de permeabilidade inferiores a $10^{-6} \mathrm{~cm} . \mathrm{s}^{-1}$ 
(Zuquette, 1981). Em extensas áreas da BHRF, são encontrados afloramentos da Formação Botucatu com origem de parte das Areias Quartzozas Profundas (Nishiyama, 1991; Failache \& Zuquette, 2018) e com maior permeabilidade, em torno de $10^{-3}$ a $10^{-2} \mathrm{~cm}_{\mathrm{seg}}{ }^{-1}$, o que configura a área como recarga pertencente ao Sistema Aquífero Guarani (Zuquette, 1981; Oliveira \& Prado, 1984). A Formação Itaqueri é composta de arenitos de origem flúvio lacustres e comporta-se como aquífero livre (Gonçalves, 1986; Aguiar, 1989).

\section{MATERIAIS E MÉTODOS}

Os resultados na BHRF foram gerados a partir de SIG Idrisi Andes 15.0 no sistema de coordenadas planas UTM, datum SIRGAS 2000, fuso 23 Sul. A Tabela 1 apresenta os materiais utilizados e suas respectivas fontes de dados. As digitalizações de vetores foram realizadas no software Global Mapper 11.

$\mathrm{O}$ método está fundamentado em estudos com os modelos elaborados por Ross (1994)

(AEFANA), Ruhoff et al. (2005) (ZVA) e Wischmeier \& Smith (1978) (USLE). Os resultados da análise comparativa dos ZVA AEFANA por índices de dissecação e classes de declividade estão fundamentados em Cunha et al. (2011) e a EPS (USLE) em Luz (2012), Cavalcante (2013) e Luz et al. (2017). Na Figura 2 é apresentado o esquema da metodologia aplicada.

Tabela 1 - Materiais empregados no estudo.

\begin{tabular}{c|c|c}
\hline Dado & Origem & Fonte \\
\hline Declividade & $\begin{array}{c}\text { Cartas topográficas de São Carlos (SF-23-Y-A-I-1) e } \\
\text { Corumbataí (SF-23-Y-A-I-2), escala 1:50.000 }\end{array}$ & IBGE (1972) \\
\hline Geomorfologia & Carta geomorfológica (SF-23-Y-A-I), escala 1:100.000 & Nishiyama (1991) \\
\hline Geologia & Carta geológica (SF-23-Y-A-I), escala 1:100.000 & Nishiyama (1991) \\
\hline Pedologia & Carta pedológica (SF-23-Y-A-I), escala 1:100.000 & Oliveira \& Prado (1984) \\
\hline $\begin{array}{c}\text { Pluviosidade } \\
\text { Uso e cobertura do } \\
\text { solo }\end{array}$ & $\begin{array}{c}\text { Normais climatológicas de 1961 a 1990 do banco de dados do } \\
\text { Imagem ALOS, sensor AVNIR-2 (12/11/2006), resolução } \\
\text { espacial de 10 metros }\end{array}$ & Cunha et al. (2011) \\
\hline
\end{tabular}

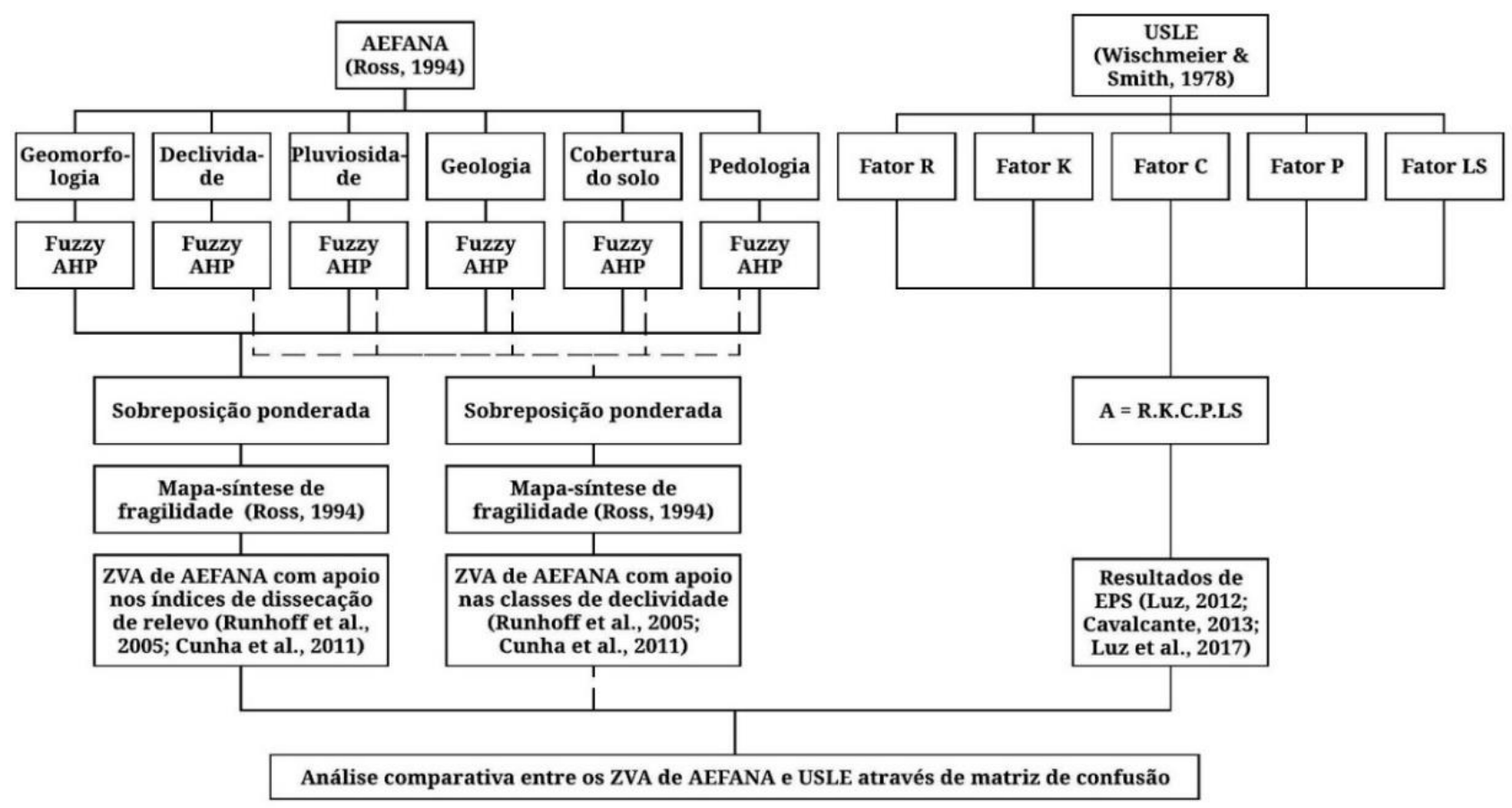

Figura 2 - Fluxograma do método utilizado para estudo de caso na BHRF.

\section{Zoneamento da Vulnerabilidade Ambiental}

As variáveis determinantes para a aplicação do zoneamento no presente estudo referem-se às classes de pluviosidade, geologia, cobertura do solo, pedologia e geomorfologia (no caso de apoio nos índices de dissecação de relevo) ou declividade (no caso de apoio à classe homônima). 
Determinação das Fragilidades Ambientais das Variáveis

Segundo Cunha et al. (2011), para determinação das vulnerabilidades ambientais, as técnicas de inferências geográficas FuzzyAHP permitem comparar as classes de variáveis entre si com um critério de importância relativa que indica a intensidade da fragilidade.

Sendo assim, em cada uma das cinco variáveis apoiadas nos índices de dissecação do relevo ou nas classes de declividade, foram determinados os valores das fragilidades frente aos processos erosivos, ponderadas de acordo com suas características em cinco categorias: muito fraca $(0,1)$, fraca $(0,3)$, média $(0,5)$, forte $(0,7)$ e muito forte $(0,9)$ (Barbosa \& Cordeiro, 2001).

As unidades mais estáveis apresentam valores mais próximos de 0,1 , as intermediárias ao redor de 0,5 e as mais vulneráveis próximas de 0,9 (Câmara et al., 2001).
Para determinação das fragilidades das feições geomorfológicas, realizou-se a sobreposição das cartas topográficas e da carta geomorfológica, tendo-se como referência os perfis topográficos, os valores dos entalhamentos médio dos vales e a dimensão média interfluvial das classes de geomorfologia, resultando em índices de dissecação do relevo (Tabela 2) (Ross, 2001; Cunha et al., 2011).

Por meio da ponderação das fragilidades das classes de geomorfologia através dos índices de dissecação do relevo propostos por Ross (1994), obteve-se as importâncias conforme Tabela 3, em (a).

Nas hierarquizações das variáveis de relevo (dissecação e declividade), levou-se em consideração as intensidades dos processos erosivos, os riscos potenciais de escorregamentos/deslizamentos e a velocidade de transformações de relevos.

Tabela 2 - Matriz dos índices de dissecação do relevo (Modificado de Ross, 2001).

\begin{tabular}{c|c|c|c|c|c|c}
\hline \multicolumn{2}{c|}{ Inter-Relação } & \multicolumn{5}{c}{ Dimensão interfluvial média em metros } \\
\hline Entalhamento médio dos vales & $>3750(1)$ & 1750 a $3750(2)$ & 750 a $3750(3)$ & 250 a $750(4)$ & $<250(5)$ \\
\hline$<40 \mathrm{~m}$ & $(1)$ & 11 & 12 & 13 & 14 & 15 \\
\hline 40 a $80 \mathrm{~m}$ & $(2)$ & 21 & 22 & 23 & 24 & 25 \\
\hline 80 a $160 \mathrm{~m}$ & $(3)$ & 31 & 32 & 33 & 34 & 35 \\
\hline 160 a $240 \mathrm{~m}$ & $(4)$ & 41 & 42 & 43 & 44 & 45 \\
\hline$>240 \mathrm{~m}$ & $(5)$ & 51 & 52 & 53 & 54 & 55 \\
\hline
\end{tabular}

A variável de declividade, em (b), foi classificada segundo intervalos já consagrados na literatura referente a estudos de capacidade de uso e aptidão agrícola, associados aos valores já conhecidos de limites críticos de geotecnia (Spörl \& Ross, 2004).

Em (c), na pluviosidade, a quantidade e a distribuição das chuvas exercem uma forte ação mecânica em solos com pouca cobertura vegetal e, quando associadas a relevos acentuados, acarretam no aumento significativo da velocidade de escoamento superficial, podendo ter os fatores litológicos e pedológicos ainda mais favoráveis a erosão (Ruhoff, 2004).

Assim, as características do clima foram hierarquizadas devido à maior ou menor intensidade de chuvas na influência da dinâmica dos ambientes, utilizando como base de referência o mapa climatológico anual por obtido por meio do software GrADs 2.0 a partir dos domínios climáticos que ocorrem no Brasil.

Em (d), as vulnerabilidades das formações geológicas frente aos processos erosivos consideram os graus de agregação das partículas e a resistência aos processos erosivos (Ruhoff et al., 2005).

Em (e), para a determinação das fragilidades segundo a cobertura do solo, considerou-se o disposto por Ross $(1990,1994)$ e Oliveira \& Chaves (2009), que propuseram uma hierarquização da cobertura vegetal obedecendo à ordem decrescente quanto à capacidade de proteção aos solos.

O uso e cobertura do solo foi obtido no SIG Spring 5.0 por meio da classificação supervisionada (máxima verossimilhança) de imagem de satélite ALOS, em composição colorida falsa-cor (3R, $2 \mathrm{G}$ e $1 \mathrm{~B})$.

Por fim, em (f), a hierarquização das classes de erodibilidade dos solos considerou $\mathrm{o}$ escoamento superficial difuso e concentrado. $\mathrm{O}$ tipo de solo e suas características intrínsecas (textura, estrutura, porosidade, profundidade e pedregosidade) fornecem maior ou menor resistência do mesmo ao processo de erosão (Ross, 1994). 
Tabela 3 - Importância das variáveis nos processos erosivos e inferência Fuzzy-AHP.

\begin{tabular}{|c|c|c|}
\hline $\begin{array}{c}\text { Classes de } \\
\text { fragilidade }\end{array}$ & Variáveis & $\begin{array}{r}\text { Fuzzy } \\
\text { AHP }\end{array}$ \\
\hline & (a) Índice de dissecação do relevo* & \\
\hline Muito baixa & 11 & 0,1 \\
\hline Baixa & $21,22,12$ & 0,3 \\
\hline Média & $31,32,33,13,23$ & 0,5 \\
\hline Alta & $41,42,43,44,14,24,34$ & 0,7 \\
\hline \multirow[t]{2}{*}{ Muito alta } & $51,52,53,54,55,15,25,35,45$ & 0,9 \\
\hline & (b) Classes de declividade* & \\
\hline Muito fraca & $<6 \%$ & 0,1 \\
\hline Fraca & $6-12 \%$ & 0,3 \\
\hline Média & $12-20 \%$ & 0,5 \\
\hline Forte & $20-30 \%$ & 0,7 \\
\hline \multirow[t]{2}{*}{ Muito forte } & $>30 \%$ & 0,9 \\
\hline & (c) Características pluviométricas** & \\
\hline Muito fraca & $\begin{array}{l}\text { Situação pluviométrica com distribuição regular ao longo do ano, com volumes anuais } \\
\text { não muito superiores a } 1000 \mathrm{~mm}^{-a_{n}{ }^{-1}}\end{array}$ & 0,1 \\
\hline Fraca & $\begin{array}{l}\text { Situação pluviométrica com distribuição regular ao longo do ano, com volumes anuais } \\
\text { não muito superiores a } 2000 \mathrm{~mm}^{-\mathrm{ano}^{-1}}\end{array}$ & 0,3 \\
\hline Média & $\begin{array}{c}\text { Situação pluviométrica com distribuição anual desigual, com períodos secos entre } 2 \text { e } 3 \\
\text { meses }\end{array}$ & 0,5 \\
\hline Forte & $\begin{array}{c}\text { Situação pluviométrica com distribuiçãa anual desigual, com períodos secos entre } 3 \text { e } 6 \\
\text { meses, e alta concentração das chuvas nos períodos chuvosos }\end{array}$ & 0,7 \\
\hline \multirow[t]{2}{*}{ Muito forte } & $\begin{array}{l}\text { Situação pluviométrica com distribuição regular, ou não, ao longo do ano, com grandes } \\
\text { volumes anuais ultrapassando } 2500 \mathrm{~mm} \cdot \text { ano }^{-1} \text {; ou ainda, comportamentos pluviométricos } \\
\text { irregulares ao longo do ano, com episódios de chuvas de alta intensidade e volumes } \\
\text { anuais baixos, geralmente abaixo de } 900 \mathrm{~mm} \cdot \text { ano }^{-1} \text { (semiárido) }\end{array}$ & 0,9 \\
\hline & (d) Classes de formações geológicas* & \\
\hline Muito baixa & Riolito Serra Geral & 0,1 \\
\hline Baixa & Basalto Serra Geral & 0,3 \\
\hline Média & Formação Rosário do Sul & 0,5 \\
\hline Alta & Formação Botucatu & 0,7 \\
\hline \multirow[t]{2}{*}{ Muito alta } & Formação Aluvial & 0,9 \\
\hline & (e) Classes de cobertura do solo* & \\
\hline Muito fraca & Florestas e matas naturais com biodiversidade & 0,1 \\
\hline Fraca & Formações arbustivas naturais, matas secundarias, cerrados e capoeiras & 0,3 \\
\hline Média & Cultivos de ciclos longos, pastagens com baixo pisoteio de gado, silvicultura & 0,5 \\
\hline Forte & Culturas de ciclo longo com baixa densidade, culturas de ciclo curto & 0,7 \\
\hline \multirow[t]{2}{*}{ Muito forte } & Áreas desmatadas, solo exposto, agricultura não-conservacionista & 0,9 \\
\hline & (f) Classes de solos* & \\
\hline Muito fraca & Latossolo roxo, latossolo vermelho escuro e vermelho amarelo de textura argilosa & 0,1 \\
\hline Fraca & Latossolo amarelo e vermelho, de textura média argilosa & 0,3 \\
\hline Média & $\begin{array}{c}\text { Latossolo vermelho amarelo, terra roxa, terra Bruna, solos podzólicos vermelho amarelo } \\
\text { de textura média argilosa }\end{array}$ & 0,5 \\
\hline Forte & Podzólicos vermelho amarelo de textura médio-arenosa e cambissolos & 0,7 \\
\hline Muito forte & Podzólicos, litólicos e areias quartzosas & 0,9 \\
\hline
\end{tabular}

*Modificado de Ross (1994), **Modificado de Ross (2001)

Sobreposição Ponderada das Variáveis pedologia com o índice de dissecação do relevo, Ambientais e em seguida as mesmas variáveis foram

Após estabelecimento da classificação da fragilidade dos planos de informação, realizou-se a sobreposição ponderada das variáveis de pluviosidade, geologia, cobertura do solo e ponderadas com a declividade. Consequentemente, foram obtidos dois mapassíntese de fragilidade ambiental.

Utilizando os critérios de Ruhoff et al. (2005), 
os zoneamentos foram classificados por Cunha et al. (2011) em cinco classes de estabilidade transformadas em riscos ambientais, variando de 0 a 100\%, sendo: estável (até 20\%), moderadamente estável (entre 20 e 40\%), moderadamente instável (entre 40 e 60\%), instável (entre 60 e 80\%) e instabilidade emergente (acima de 80\%).

\section{Expectativa de Perda de Solo (EPS)}

A estimativa da quantidade de erosão, para bacias hidrográficas, pode ser obtida por meio da USLE proposta por Wischmeier \& Smith (1978). Por ser um modelo matemático simples de predição de perda de solo e que pode ser aplicado mesmo com poucos recursos financeiros, a USLE é uma das equações de erosão mais utilizadas no mundo (Kinnell, 2010). A equação estima a perda média anual de solo associada à erosão laminar utilizando seis fatores intrínsecos às características climáticas, propriedades do solo, topografia, vegetação e manejo do solo, sendo expressa pela Equação 1.

$$
\mathrm{A}=\mathrm{R} \text { K L S C P }
$$

Onde A é a predisposição à PS $\left(\mathrm{t} \cdot \mathrm{ha}^{-1} \cdot \mathrm{ano}^{-1}\right)$, $\mathrm{R}$ é $\mathrm{o}$ fator erosividade da precipitação (MJ.mm.ha ${ }^{-1} \cdot h^{-1} \cdot$ ano $^{-1}$ ), K é o fator erodibilidade do solo (t.h. $\mathrm{MJ}^{-1} \cdot \mathrm{mm}^{-1}$ ), L e $\mathrm{S}$ são os fatores topográficos que dependem do comprimento de rampa e gradiente de declividade (adimensionais), C é o fator de cobertura e uso do solo (adimensional) e $\mathrm{P}$ é o fator de práticas de controle de erosão (adimensional). A obtenção dos fatores conforme Luz et al. (2017) é descrita sucintamente a seguir.

(a) Erosividade da chuva (Fator R): o cálculo do fator $\mathrm{R}$ foi feito por meio do software NetErosividade que utiliza uma rede neural artificial para estimar os valores de erosividade da chuva para todo o Estado de São Paulo. Os dados de erosividade são obtidos a partir de parâmetros de entrada de latitude, longitude e altitude (Moreira et al., 2006).

(b) Erodibilidade do solo (Fator K): os valores de $\mathrm{K}$ foram obtidos a partir de consulta à literatura (Carvalho, 1994 apud Silva \& Alvares, 2005) e foram relacionados com a distribuição espacial pedológica da área.

(c) Manejo do solo (Fatores C e P): os valores de $\mathrm{C}$ foram adotados a partir de consulta à literatura para as classes temáticas presentes no mapeamento do uso e cobertura do solo realizado por Cunha et al. (2011). Os valores de P tratam das práticas conservacionistas adotadas por cada tipo de cultura. No estudo, foi considerado que não há práticas conservacionistas sendo aplicadas na área, portanto, o fator P é 1 para toda a bacia (pior cenário).

(d) Topografia (Fatores L e S): os fatores L e $S$ consideram a declividade e o comprimento da rampa na determinação da velocidade e tempo de escoamento de sedimentos. Os fatores foram obtidos conjuntamente através do software USLE-2D v.4.1 (Desmet \& Govers, 1996), utilizando como parâmetro de entrada o Modelo Digital do Terreno oriundo das cartas topográficas na escala 1:50.000.

\section{Análise Comparativa Entre os ZVA AEFANA e EPS USLE}

Para efeitos de comparação entre os ZVA e a EPS, algumas considerações foram realizadas de maneira permitir a análise dos modelos segundo classes de estabilidade (estável e instável). Para tal, no caso da AEFANA, as classes de risco ambiental superior a 20\% (moderadamente estável, moderadamente instável, instável e instabilidade emergente) foram reclassificadas para classe nomeada "instável", enquanto a estável permaneceu com a classe de mesmo nome. Já para os resultados obtidos com a EPS, foram criados diversos cenários de reclassificação com base em limites crescentes de EPS: considerou-se estáveis as EPS inferiores a $25,50,100,150,200,250,300,350,450,600$, 900 e 1000 t.ha ${ }^{-1} \cdot$ ano $^{-1}$, enquanto que, para valores acima do estipulado em cada cenário, os resultados de EPS foram reclassificados como instáveis. A abordagem empregada neste trabalho utiliza uma matriz de confusão obtida a partir da comparação dos pixels das imagens matriciais de ZVA e EPS no software Octave (Eaton et al., 2017). As imagens matriciais foram sobrepostas e, então, gerou-se uma matriz de confusão para cada cenário criado, ou seja, reclassificações de ZVA (apoiado nos índices de dissecação de relevo e nas classes de declividade, sendo considerados como verdade) $\mathrm{x}$ EPS. A matriz de confusão para um problema que envolve a análise de duas classes é de tamanho $2 \times 2$, na qual a diagonal principal corresponde ao número de acertos para cada classe. Os demais elementos representam erros de classificação. A abordagem empregada define como acerto o que dentro da AEFANA é definido como estável e na EPS também, e assim para a classe instável, ou seja, contabilizando pixels igualmente classificados entre os diferentes modelos. 


\section{RESULTADOS E DISCUSSÃO}

Zoneamento da Vulnerabilidade Ambiental (ZVA)

A Figura 3, em (a) e (b), apresenta os mapassíntese dos resultados de ZVA conforme Cunha et al. (2011), tanto no apoio no índice de dissecação do relevo quanto nas classes de declividade, respectivamente.

Para o ZVA obtido com apoio no índice de dissecação do relevo (Figura 3a), a distribuição das classes em polígonos regulares está associada principalmente ao padrão espacial da variável de cobertura do solo dentro da BHRF. O mesmo não ocorre na fragilidade ambiental encontrada para a declividade (Figura 3b), indicando a menor sensibilidade desse modelo em considerar as atividades antrópicas. Os resultados comparativos entre as fragilidades ambientais dos ZVA indicam que o modelo baseado no índice de dissecação do relevo é mais restritivo que o modelo apoiado na declividade.

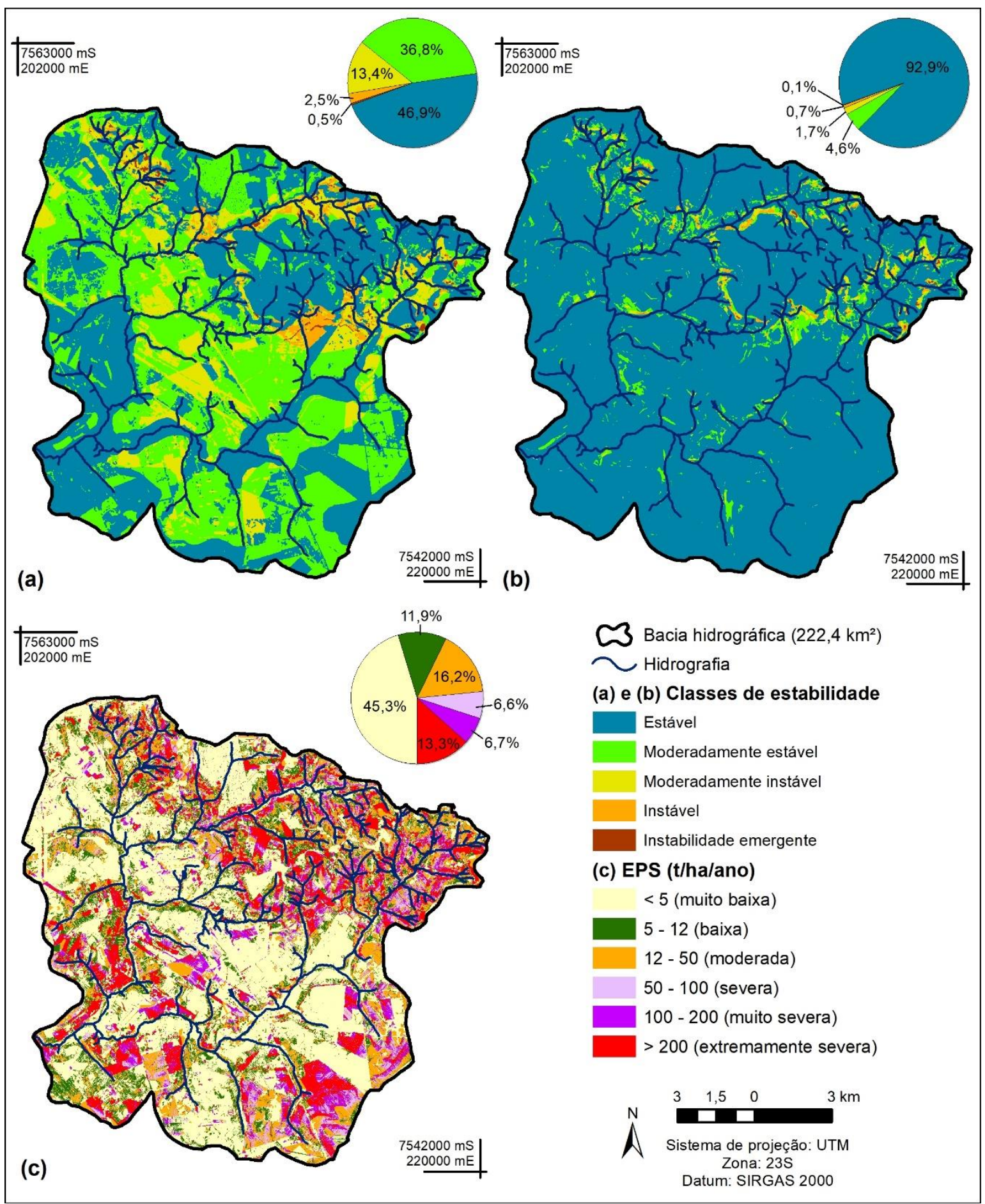

Figura 3 - ZVA com apoio em (a) índices de dissecação de relevo e (b) classes de declividades (Cunha et al., 2011), e (c) EPS para a BHRF (Cavalcante, 2013; Luz et al., 2017). 
Em conformidade com Manfré et al. (2013), que avaliou três diferentes modelos de fragilidade ambiental incluindo os ZVA em análise nesse estudo, a fragilidade obtida a partir da declividade apresenta aspecto fragmentado em relação ao componente geomorfológico, sendo que os modelos também apresentaram expressivas diferenças. Em Manfré et al. (2013), no entanto, o ZVA baseado na declividade apresentou resultados mais conservadores em relação ao índice de dissecação de relevo. A divergência nos resultados pode ser explicada pelos diferentes pesos estabelecidos às variáveis determinantes, bem como pela ausência da consideração da variável de geologia pelos autores.

Observando-se a influência das variáveis determinantes sobre as áreas críticas, como as representadas pelas classes instável e de instabilidade emergente (isto é, com riscos ambientais acima de 60\%), verificou-se que as variáveis de relevo foram as mais significantes em ambos os modelos, incidindo em $31,6 \%$ e $23,3 \%$ da área total respectivamente para as fragilidades pelo índice de dissecação de relevo e pela declividade.

No primeiro caso, as feições geomorfológicas de encostas sulcadas por vales subparalelos seguidos pelos morros arredondados são as maiores influenciadoras. No segundo caso, obteve-se uma maior influência das declividades acima de 30\%, localizadas às bordas escarpadas da província geomorfológica das Cuestas Basálticas. A variável de uso do solo também é importante para minimização ou maximização de impactos sobre a aceleração dos processos erosivos na bacia, sendo a cobertura do solo pelo cultivo de laranja foi a que mais influenciou os dois modelos aplicados. A Figura 4 apresenta os mapas temáticos das principais variáveis determinantes tanto para os modelos de ZVA quanto para a EPS.

\section{Expectativa de Perda de Solo (EPS) (USLE)}

A Figura 3 (c) apresenta o mapa de EPS de acordo com os resultados de Luz (2012), Cavalcante (2013) e Luz et al. (2017). Segundo a escala de EPS (Irvem et al., 2007), os resultados de perda de solo indicam que mais de um quarto da bacia $(42,8 \%)$ se apresenta sob significativo risco de erosão, isto é, com EPS superiores a 12 t.ha ${ }^{1}$. ano $^{-1}$ (correspondente a perda de solo moderada, severa, muito severa e extremamente severa).

Embora a erosividade da chuva (fator $\mathrm{R}$ ) exerça grande influência, seu valor não varia espacialmente na escala da bacia. Assim, identificou-se que os fatores mais influentes na distribuição dos valores do modelo na BHRF são a cobertura do solo e o fator LS, conforme Figura 4 (a) e (d). As atividades antrópicas representadas pelo solo exposto associado às culturas perenes, o cultivo de laranja e a cana-deaçúcar possuem fator $\mathrm{C}$ alto, cujos valores favorecem a erosão e são responsáveis por serem respectivamente as classes predominantes em EPS superiores a 100 t.ha ${ }^{-1}$. no $^{-1}$. Já o fator LS na bacia demonstra que em $40 \%$ da área a deposição é maior do que o carreamento de sedimentos (fator LS < 1), em que o relevo atua como amenizador do processo erosivo. Nestes locais concentram-se os sedimentos e a poluição carreados das partes a montante, nas porções mais altas da bacia.

\section{Análise Comparativa Entre os ZVA AEFANA e a EPS USLE}

Os resultados de taxas de acerto obtidos pela matriz de confusão para a análise comparativa entre os modelos que determinam a vulnerabilidade ambiental são apresentados na Figura 5. Os dados computados na matriz de confusão consideram o ZVA como verdade, sendo assim, a taxa de acerto representa a correspondência entre os dados de EPS USLE em relação aos modelos de ZVA AEFANA (imagem de classes "corretas" de pixels).

Através da matriz de confusão entre a EPS e ZVA com apoio nos índices de dissecação, verificou-se pela Figura 5 (a) que a taxa de acerto se eleva de $69,9 \%$ para os pixels da classe estável no cenário de EPS de até 25 t.ha ${ }^{-1} \cdot$ ano $^{-1}$ para 98,0\% com EPS de até 1000 t.ha ${ }^{-1} \cdot$ ano $^{-1}$. O aumento no número de pixels da classe estável para a USLE, portanto, implica em uma maior semelhança com o modelo de ZVA em análise. Por outro lado, ao se observar as classes de instabilidade, a taxa de acerto no primeiro cenário é de apenas $37,2 \%$, isto é, pouco mais de um terço dos pixels da classe instável da imagem de EPS de até 25 t.ha $^{-1}$.ano ${ }^{-1}$ coincidiu com a mesma classe na imagem de ZVA. A diferença é acentuada com o aumento do limite superior de EPS, caindo para uma concordância de apenas 5,1\% para EPS de até 1000 t.ha ${ }^{-1}$. ano $^{-1}$. O resultado médio de acerto da USLE em relação ao modelo de ZVA apoiado nos índices de dissecação, considerando as duas classes, reduz de $52,5 \%$ no primeiro cenário para $48,6 \%$ no último. 


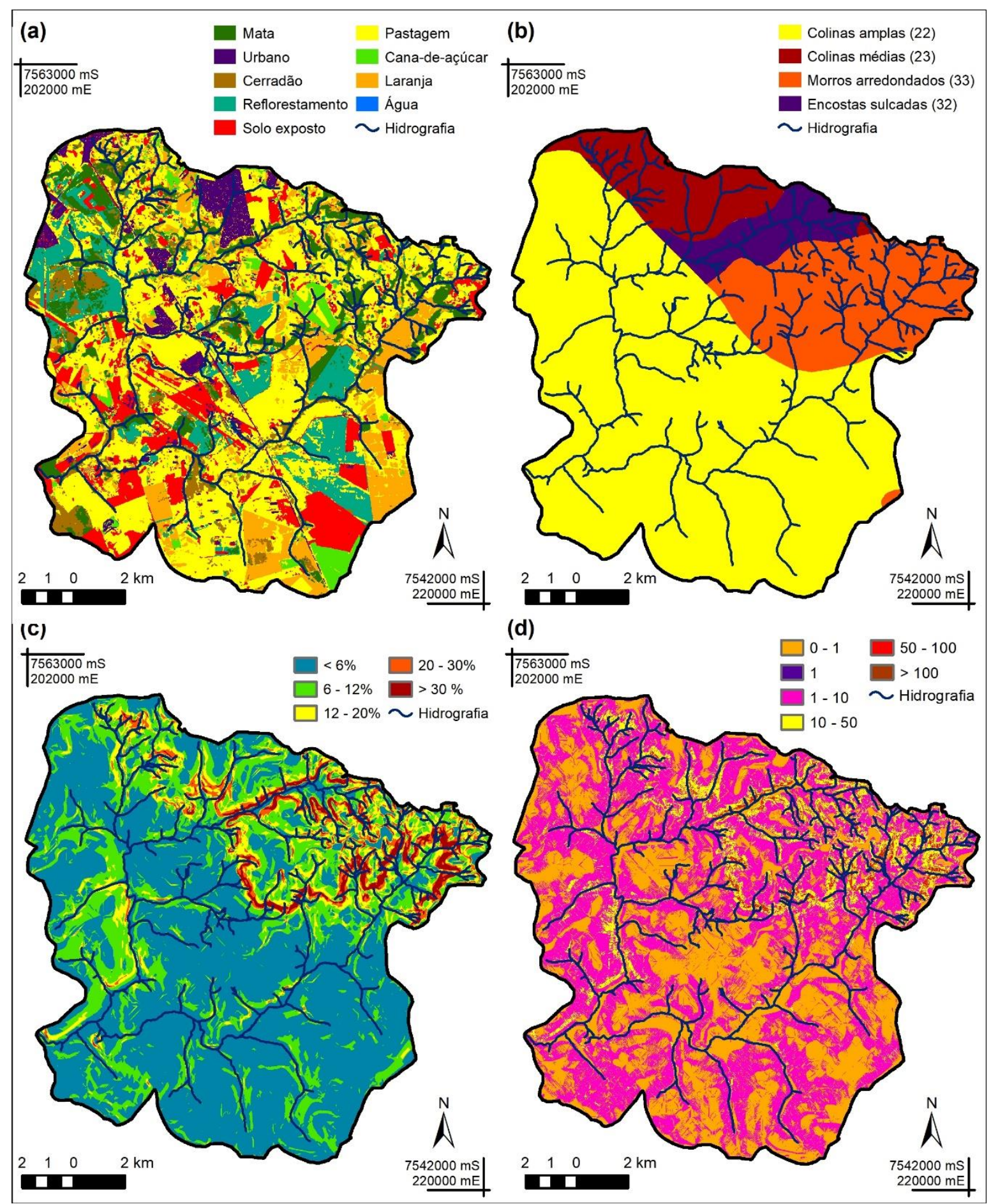

Figura 4 - Variáveis mais significantes na determinação da fragilidade ambiental dos modelos: (a) cobertura do solo; (b) geomorfologia e respectivo índice de dissecação de relevo; (c) declividade (\%) e (d) fator LS (adimensional).

Já para os resultados de comparação entre a USLE e o modelo de ZVA com apoio nas classes de declividade, conforme Figura 5 (b), a matriz de confusão indicou comportamento semelhante à comparação anterior. Em curva crescente, a taxa de acerto eleva de $69,2 \%$ a $97,7 \%$ para a classe estável considerando o primeiro e último cenário, enquanto que, de forma decrescente, a concordância cai de $74,4 \%$ a $21,0 \%$ para a classe instável nas mesmas situações. O resultado de acerto geral acompanha a curva de acerto para a classe estável, passando de $69,6 \%$ a $92,3 \%$. No entanto, neste caso, a matriz reflete a presença significativamente maior da quantidade de pixels da classe estável em relação à instável do modelo de ZVA com apoio nos índices de dissecação.

Os resultados alcançados demonstraram que à medida que o limite de EPS aumenta, há também um aumento no número de pixels correspondentes para a classe estável. Com relação à classe instável, esta relação se inverte, ou seja, quanto maior o EPS, menor a 
correspondência entre os pontos classificados como instáveis nas duas imagens. Pelo fato de a análise tratar de dados gerados de forma totalmente independente, a coincidência entre os pixels do mapa analisado e o mapa verdade seria um forte indício de que os métodos geram informações correlatas sobre a vulnerabilidade ambiental.

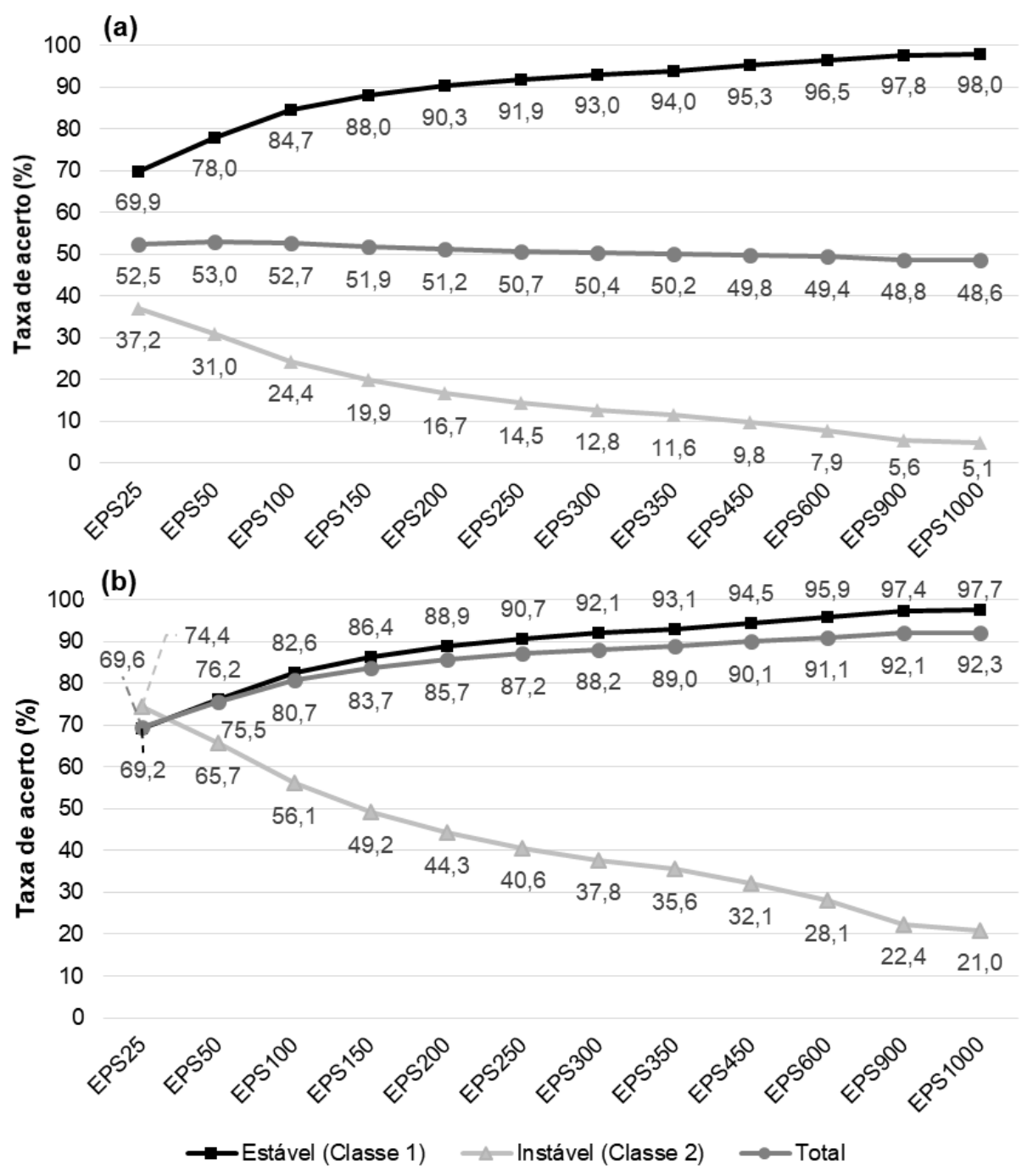

Figura 5 - Taxas de acerto entre os cenários de EPS da USLE e os ZVA AEFANA com apoio em (a) índices de dissecação de relevo e (b) classes de declividade.

Ao analisar a classe instável como aquela capaz de representar a vulnerabilidade ambiental, obtém-se de maneira geral baixas correspondências entre a USLE e os modelos de ZVA. Considerando a escala de Irvem et al. (2007), em que valores de PS a partir de 50 t.ha ${ }^{1}$. ano $^{-1}$ representam perdas de solo severas, as taxas de acerto dessa classe pela USLE foram de $31,0 \%$ e $65,7 \%$ em relação ao ZVA com apoio no índice de dissecação de relevo e nas classes de declividade, respectivamente.

Apesar de a USLE apresentar inicialmente maior correlação com os modelos de ZVA, a redução da taxa de acerto de classe instável com o aumento dos limites de EPS nos diferentes cenários indica que a USLE identifica as áreas mais suscetíveis ambientalmente (isto é, com perdas mais severas) em áreas não coincidentes com a vulnerabilidade ambiental determinada pelo ZVA. Tal fato pode ser observado através da Figura 6, que apresenta a distribuição espacial das coincidências e erros do cruzamento dos cenários de EPS de 50 e 1000 t.ha $^{-1}$.ano ${ }^{-1}$ com os modelos de ZVA.

Baseado nos dados da Figura 6 (a) e (b), notase que, para o intervalo de perdas de até 50 t.ha ${ }^{1}$.ano ${ }^{-1}$, a fragilidade ambiental mapeada pela USLE é mais restritiva que aquela do ZVA de declividade. Pela USLE, as perdas severas e extremamente severas são distribuídas ao longo da bacia, enquanto o modelo de ZVA foi fortemente influenciado pelas declividades acima de $30 \%$, bem como, na região mais ao norte da bacia por meio de morros com 
ondulações mais acentuadas.

Por outro lado, de acordo com a Figura 6 (c) e (d), verifica-se que o ZVA apoiado nos índices de dissecação apresenta-se mais conservador do que a USLE, especialmente na região englobada pela direção NO/SE da bacia. Nessas áreas, predomina-se a classe de risco moderadamente estável, equivalente ao risco ambiental potencial entre 20 e $40 \%$ (Ruhoff et al., 2005). A presença de polígonos nessa região, por sua vez, associase principalmente com a maior sensibilidade do modelo em considerar as demais variáveis ambientais cujas fragilidades mais fortes equilibram-se com a topografia baixa.

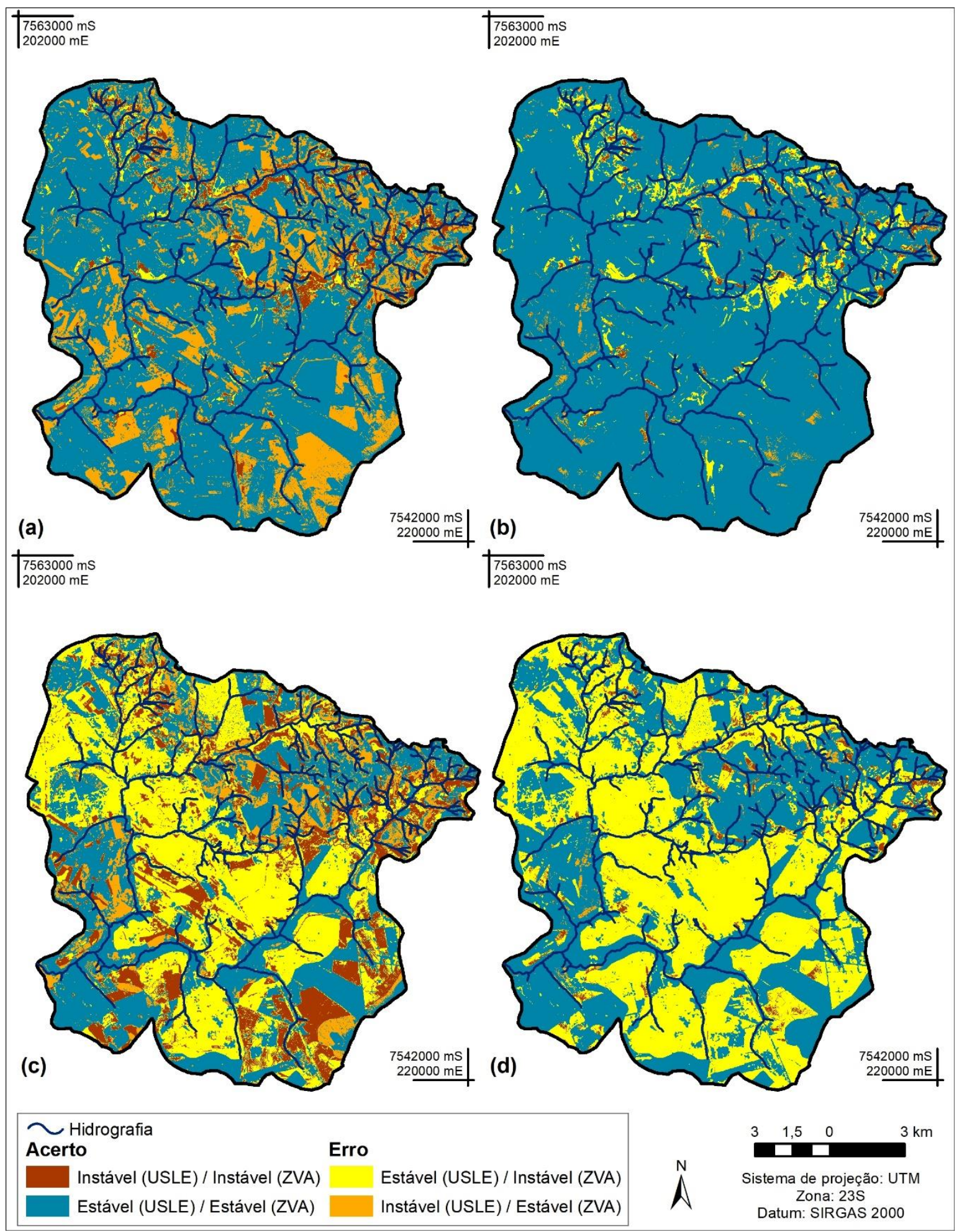

Figura 6 - Mapas de sobreposição para comparação entre a USLE e ZVA: cenários de EPS de até 50 e 1000 t.ha ${ }^{-1}$.ano ${ }^{-1}$, respectivamente, para o ZVA com apoio nas classes de declividade (a e b) e nos índices de dissecação (c e d).

A USLE, no entanto, é fortemente influenciada distribuição espacial da capacidade de transporte pelo fator topográfico, o qual permite definir a de sedimentos na bacia, indicando a participação 
do relevo na intensificação do processo erosivo. Nesse modelo, valores altos de fator LS, principalmente quando associados com atividades antrópicas (em especial solo exposto, cana de açúcar e laranja), foram determinantes na delimitação das áreas de fragilidade ambiental a partir da EPS, inclusive em locais não indicados pelo ZVA (como na porção SW e nas cabeceiras de rios ao NE da bacia).

Ademais, o fator LS apresentou grande influência na EPS mesmo em locais onde predominam cobertura de mata ciliar, reflorestamento e cerradão. Já nas zonas planas, as grandes perdas de solo estão relacionadas aos usos do solo para a agricultura. Pela análise de fragilidade ambiental a partir da EPS da USLE, verifica-se que a região NO da bacia apresenta menores riscos de erosão, enquanto a $\mathrm{NE}$ se destaca por apresentar os maiores riscos de intensificação dos processos erosivos, sendo composta por importantes nascentes nas maiores cotas altimétricas da bacia. Costa et al. (2018) e Failache \& Zuquette (2018) verificaram que, de fato, na porção NE prevalecem as principais áreas fontes de geração de escoamento superficial, sendo que, segundo Costa et al. (2018), a região englobada pela direção NE/SO é sujeita a um grande potencial de erosão acelerada.

Nessas áreas, portanto, devem ser adotadas práticas de manejo severas no uso do solo para que sejam reduzidas a energia e velocidade da água a fim de evitar processos erosivos, assoreamento dos canais de drenagem, inundação e contaminação das águas superficiais (Failache \& Zuquette, 2018).

Contudo, Costa et al. (2018) verificaram também grandes potenciais de erosão na direção $\mathrm{NO} / \mathrm{SE}$, região levantada como moderadamente estável pelo ZVA apoiado nos índices de dissecação. Para os autores, a presença de solos arenosos, a pecuária extensiva e o cultivo da canade-açúcar foram fatores determinantes que apresentaram relação direta com a maioria das ocorrências de ravinas e voçorocas na bacia segundo sua metodologia calibrada para determinação do potencial de erosão acelerada, que considerou atributos específicos como formas de vertentes, densidade de drenagem e textura, profundidade e permeabilidade dos solos.

É importante destacar que, caso o modelo proposto por Ross (1994) fosse considerado por essa metodologia como "instável" a partir do risco ambiental potencial acima de $40 \%$, o modelo da USLE para perdas de solo severa, muito severa ou extremamente severa apresentaria resultados de vulnerabilidade ambiental mais conservadores na área em estudo.

É viável, portanto, considerar a USLE como um modelo de vulnerabilidade ambiental apesar das diferenças frente ao ZVA, desde que sejam resguardadas as devidas precauções na correta interpretação dos parâmetros utilizados bem como nos objetivos da análise. Conforme observado por Aretano et al. (2015), a quantificação da vulnerabilidade não se resume a uma tarefa simples, pois não se reduz a uma única métrica e envolve a qualidade dos dados utilizados e a percepção e preferências dos tomadores de decisão.

Nesse sentido, a USLE fornece uma avaliação coerente sobre a influência dos modelos de análise de vulnerabilidade ambiental na bacia, permitindo correlacionar problemas de susceptibilidade à erosão e perdas de solo aos modelos de ZVA para uma abordagem calibrada, sistêmica e integrada da área avaliada.

\section{CONSIDERAÇÕES FINAIS}

O presente estudo visou verificar a possibilidade de adoção do modelo USLE na determinação do ZVA, com enfoque em sua capacidade de estimar os riscos de erosão e assim oferecer resultados que auxiliem a gestão de bacias hidrográficas.

Baseado nos resultados de análise comparativa, verificou-se que as diferenciadas formas de análises na determinação da fragilidade ambiental pelos modelos da USLE e de ZVA com apoio nos índices de dissecação de relevo e nas classes de declividade, mesmo considerando fatores semelhantes, representaram diferenças consideráveis na determinação final da vulnerabilidade.

As baixas taxas de acerto obtidas entre os resultados referentes à classe de instabilidade refletiram o grau da influência dos fatores em cada modelo aplicado à BHRF. A comparação das influências das variáveis entre os próprios modelos de ZVA indicou que os maiores riscos ocorrem sempre nas mesmas classes de variáveis, principalmente de relevo, uso do solo e pedologia.

O modelo baseado no índice de dissecação do relevo, no entanto, apresenta restrições mais 
amplas que o modelo apoiado na declividade. Já na USLE, as EPS na bacia estão relacionadas principalmente à forte influência da cobertura do solo e do fator topográfico.

Pela metodologia proposta, as maiores proporções de instabilidades mapeadas ocorrem respectivamente no ZVA baseado no índice de dissecação de relevo, na USLE e, por último, no ZVA baseado na declividade.

As discrepâncias espaciais entre os modelos de ZVA de índice de dissecação de relevo e a USLE indicam que o primeiro agregou mais valor às classes pedológicas e de geologia, porém, não possuiu a mesma capacidade do segundo em discriminar as áreas onde o relevo, especialmente em conjunto com o uso do solo, ameniza ou intensifica os processos erosivos, principalmente na região de cabeceira de rios da bacia.

Conclui-se que a determinação da fragilidade ambiental pela USLE é viável, tendo em vista que a predição de erosão hídrica em mananciais fornece subsídios para adoção de práticas de controle, seleção de áreas prioritárias ao planejamento de serviços ambientais pontuais e priorização de ações conservacionistas.

Destaca-se, no entanto, a importância da integração de informações para a análise coerente da vulnerabilidade ambiental de bacias hidrográficas, associando metodologias e inclusive análises in loco para aperfeiçoamento das modelagens ambientais.

\section{AGRADECIMENTOS}

\section{Agradecimentos a CAPES pelo apoio financeiro.}

\section{REFERÊNCIAS}

AGUIAR, R.L. Mapeamento geotécnico da área de expansão urbana de São Carlos-SP: Contribuição ao planejamento. São Carlos, 1989. 164 p. Dissertação (Mestre em Geotecnia) - Escola de Engenharia de São Carlos, Universidade de São Paulo.

ARETANO, R.; PETROSILLO, I.; ZACCARELLI, N.; SEMERARO, T.; ZURLINI, G. People perception of landscape change effects on ecosystem services in small Mediterranean islands: A combination of subjective and objective assessments. Landscape and Urban Planning, v. 112, p. 63-73, 2013.

ARETANO, R.; SEMERARO, T.; PETROSILLO, I.; DE MARCO, A.; PASIMENI, M. R.; ZURLINI, G. Mapping ecological vulnerability to fire for effective conservation management of natural protected areas. Ecological Modelling, v. 295, p. 163-175, 2015.

BARBOSA, C.C.F. \& CORDEIRO, J.P.C. Manual de referência em LEGAL. In: CÂMARA, G.; DAVIS, C.; MONTEIRO, M.V.M. (Coords.), Introdução à Ciência da Geoinformação. Apêndice A. São José dos Campos: INPE, p. 325-345, 2001.

CÂMARA, C.; MOREIRA, F.R.; BARBOSA FILHO, C. R.A.; BÖNISCH, S. Técnicas de Inferência Geográfica. In: CÂMARA, G.; DAVIS, C.; MONTEIRO, M.V.M. (Coords.), Introdução à Ciência da Geoinformação. São José dos Campos: INPE, p. 241-288, 2001.

CARVALHO, N.O. Hidrossedimentologia prática. Rio de Janeiro: CPRM, 372 p., 1994.

CAVALCANTE, T.D.M. Área de preservação permanente e erosão do solo, em bacia hidrográfica de manancial urbano. Estudo do caso do Ribeirão do Feijão, São Carlos-SP Itajubá, 2013, 91 p. Dissertação (Mestrado em Meio Ambiente e Recursos Hídricos) - Instituto de Recursos Naturais, Universidade Federal de Itajubá.

CENTRO DE PESQUISAS METEOROLÓGICAS E CLIMÁTICAS APLICADAS A AGRICULTURA - CEPAGRI Clima dos Municípios Paulistas. Disp. em: https://www. cpa.unicamp.br/outras-informacoes/clima_muni_549.html.

CONWAY, T.M. \& LATHROP, R.G. Alternative land use regulations and environmental impacts: assessing future land use in an urbanizing watershed. Landscape and Urban Planning, v. 71, n. 1, p. 1-15, 2005.

COSTA, C.W.; LORANDI, R.; LOLLO, J.A.; IMANI, M.; DUPAS, F.A. Surface runoff and accelerated erosion in per urban wellhead area in southeastern Brazil. Environmental Earth Sciences, v. 77, p. 1-18, 2018.

COSTA, C.W.; LORANDI, R.; LOLLO, J.A.; SANTOS, V.S.
Potential for aquifer contamination of anthropogenic activity in the recharge area of the Guarani Aquifer System, southeast of Brazil. Groundwater for Sustainable Development, v. 8, p. 10-23, 2019.

CUNHA, R.C.; DUPAS, F.A.; PONS, N.A.D.; TUNDISI, J.G. Análise da influência das variáveis ambientais utilizando inferência fuzzy e zoneamento das vulnerabilidades: estudo de caso da bacia hidrográfica do Ribeirão do Feijão, São Carlos, SP. Geociências, v. 30, n. 3, p. 399-414, 2011.

DAI, X.; LI, Z.; LIN, S.; XU, W. Assessment and zoning of ecoenvironmental sensitivity for a typical developing province in China. Stochastic Environmental Research and Risk Assessment, v. 26, n. 8, p. 1095-1107, 2012.

DESMET, P.J.J. \& GOVER, G. A GIS-procedure for automatically calculating the USLE LS factor on topographically complex landscape units. Journal of Soil and Water Conservation, v. 51, n. 5, p. 42-433, 1996.

DUDA, R.O.; HART, P.E.; STORK, D.G. Pattern classification. Nova Iorque: John Wiley \& Sons, 654 p., 2000.

EATON, J.W.; BATEMAN, D.; HAUBERG, S. GNU Octave version 4.4.1 manual: a high-level interactive language for numerical computations. 2017. Disp. em: https://www.gnu.org/software/octave/doc/v4.4.1/.

FAILACHE, M.F. \& ZUQUETTE, L.V. Geological and geotechnical land zoning for potential Hortonian overland flow in a basin in southern Brazil. Engineering Geology, v. 246, p. 107-122, 2018.

FERNÁNDEZ-GETINO, A.P. \& DUARTE, A.C. Soil management guidelines in Spain and Portugal related to EU Soil Protection Strategy based on analysis of soil databases. Catena, v. 126, p. 146-154, 2015.

FUNDAÇÃO SISTEMA ESTADUAL DE ANÁLISE DE DADOS - SEADE. Informações dos Municípios Paulistas. 2010. Disp. em: http://www.imp.seade.gov.br/frontend /\#/tabela

GONÇALVES, A.R.L. Geologia ambiental da área de São Carlos. São Carlos, 1986. 138 p. Tese (Doutorado em Geologia Geral e de Aplicação) Instituto de Geociências, Universidade de São Paulo.

GRECCHI, R.C.; GWYN, Q.H.J.; BÉNIÉ, G.B.; FORMAGGIO, A.R.; FAHL, F.C. Land use and land cover changes in the Brazilian Cerrado: A multidisciplinary approach to assess the impacts of agricultural expansion. Applied Geography, v.55, p.300-312, 2014.

INSTITUTO BRASILEIRO DE GEOGRAFIA E ESTATÍSTICA - IBGE. Folhas topográficas de São Carlos - 
SF-23-Y-A-I-1 e Corumbataí - SF-23-Y-A-2. 1972. Disp. em: https://www.ibge.gov.br/geociencias-novoportal/cartas-emapas/folhas-topograficas.html. Acessado em: 10 set 2018 .

INSTITUTO NACIONAL DE METEOROLOGIA - INMET. Normais Climatológicas do Brasil 1961-1990. 2009. Disponível em: http://www.inmet.gov.br/portal/index.php?r= clima/normaisclimatologicas.

IRVEM, A.; TOPALOGLU, F.; UYGYR, V. Estimating spatial distribution of soil loss over Seyhan River Basin in Turkey. Journal of Hydrology, v. 336, p. 30-37, 2007.

KARAMAGE, F.; ZHANG, C.; KAYIRANGA, A.; SHAO, H.; FANG, X.; NDAYISABA, F.; NAHAYO. L.; MUPENZI, C.; TIAN, G. USLE-Based Assessment of Soil Erosion by Water in the Nyabarongo River Catchment, Rwanda. International Journal of Environmental Research and Public Health, v. 13, n. 8, e835, 2016.

KINNELL, P.I.A. Event soil loss, runoff and the Universal Soil Loss Equation family of models: A review. Journal of Hydrology, v. 385, p. 384-397, 2010

KUNCHEVA, L.I. Combining pattern classifiers: methods and algorithms. Hoboken: John Wiley \& Sons, 350 p., 2004.

LIU, Y.; LV, X.; QIN, X.; GUO, H.; YU, Y.; WANG, J.; MAO, G. An integrated GIS-based analysis system for land-use management of lake areas in urban fringe. Landscape and Urban Planning, v. 82, n. 4, p. 233-246, 2007.LIU, D.; CAO, C.; DUBOVYK, O.; TIAN, R.; CHEN, W.; ZHUANG, Q.; ZHAO, Y.; MENZ, G. Using fuzzy analytic hierarchy process for spatio-temporal analysis of eco-environmental vulnerability change during 1990-2010 in Sanjiangyuan region, China. Ecological Indicators, v. 73, p. 612-625, 2017.

LUZ, F.G.F. Avaliação do potencial de utilização dos dados da SRTM - Shuttle Radar Topography Mission por meio da análise da perda de solo para a bacia hidrográfica do Ribeirão do Feijão, São Carlos, SP. Itajubá, 2012. 88 p. Dissertação (Mestrado em Engenharia de Energia) Universidade Federal de Itajubá.

LUZ, F.G.F.; ABE, C.A.; DUPAS, F.A.; MATOS, J.C.S.; NEVES, J. A. Avaliação do potencial de utilização dos dados da SRTM - Shuttle Radar Topography Mission por meio da análise da estimativa de perda do solo. Geociências, v. 36, n. 3 , p. 557-567, 2017.

MACHADO, F. H. \& DUPAS, F.A. Valoração de recursos hídricos como subsídio na gestão do manancial do Ribeirão do Feijão, São Carlos-SP. GEOUSP: Espaço e Tempo, v. 33, p. 111-126, 2013.

MACHADO, F.H.; SILVA, L.F.; DUPAS, F.A.; MATTEDI, A.P.; VERGARA, F.E. Environmental and economic assessment of urban watersheds: developing economic mechanisms for environmental protection of Feijão river. Brazilian Journal of Biology, v. 74, n. 3, p. 677-684, 2014.

MANFRÉ, L.A., SILVA, A.M.M; URBAN, R.C.; RODGERS, J. Environmental fragility evaluation and guidelines for environmental zoning: a study case on Ibiuna (the Southeastern Brazilian region). Environmental Earth Sciences, v. 69, p. 947-957, 2013.

MOREIRA, M.C.; CECÍLIO, R.A.; PINTO, F.A.C.; LOMBARDI NETO, F.; PRUSKI, F.F. Programa Computacional para Estimativa da Erosividade da Chuva no Estado de São Paulo Utilizando Redes Neurais Artificiais. Engenharia Agrícola, v. 14, n. 2, p. 88-92, 2006.

MUKUNDAN, R.; PIERSON, D.C.; SCHNEIDERMAN, E.M.; O'DONNEL, D.M.; PRADHANANG, S.M.; ZION, M.S.; MATONSE, A.H. Factors affecting storm event turbidity in a New York City water supply stream. Catena, v. 107, p. 80-88, 2013.

NGUYEN, A.K.; LIOU, Y.-A.; LI, M.-H.; TRAN, T.A. Zoning eco-environmental vulnerability for environmental management and protection. Ecological Indicators, v. 69, p. 100-117, 2016.
NIJS, T.C.; DE NIET, R.; CROMMENTUIJN, L. Constructing land-use maps of the Netherlands in 2030. Journal of Environmental Management, v. 72, p. 35-42, 2004.

NISHIYAMA, L. Mapeamento geotécnico preliminar da quadrícula de São Carlos-SP. São Carlos, 1991. 228 p. Dissertação (Mestrado em Geotecnia) - Escola de Engenharia de São Carlos, Universidade de São Paulo.

OLIVEIRA, J.B. \& PRADO, H. Levantamento Pedológico Semidetalhado do Estado de São Paulo: Quadrícula de São CarlosSP. Campinas: Instituto Agronômico de Campinas, 188 p., 1984.

OLIVEIRA, J.H.M. \& CHAVES, J.M. Fragilidade ambiental de um setor do raso da Catarina-BA e entorno utilizando geoprocessamento (álgebra simples de mapas-sobreposição ponderada). In: SIMPÓSIO BRASILEIRO DE GEOGRAFIA FISICA APLICADA, 13, 2009, Viçosa. Anais... Viçosa: Centro de Ciências Humanas, Letras e Artes - CCH, 2009, v. 1, p. 1-13.

OLIVEIRA, P.T.S.; SOBRINHO, T.A.; RODRIGUES, D.B.B. Erosion Risk Mapping Applied to Environmental Zoning. Water Resources Management, v. 25, n. 3, p. 1021-1036, 2011.

ROSS, J.L.S. Geomorfologia: Ambiente e Planejamento. São Paulo: Contexto, 85 p., 1990.

ROSS, J.L.S. Análise empírica da fragilidade dos ambientes naturais antropizados. Revista do Departamento de Geografia, v. 8, p. 24-30, 1994.

ROSS, J.L.S. Aplicabilidade do conhecimento Geomorfológico nos Projetos de Planejamento. In: GUERRA, A.J. \& CUNHA, S.B. (Coords.), Geomorfologia: uma atualização de bases e conceitos. Rio de Janeiro: Bertrand Brasil, p. 365-391, 2001.

RUHOFF, A.L. Gerenciamento de recursos hídricos em bacias hidrográficas: modelagem ambiental com simulação de cenários preservacionistas. Santa Maria, 2004. 107 p. Dissertação (Mestrado em Geomática) - Centro de Ciências Rurais, Universidade Federal de Santa Maria.

RUHOFF, A.L.; SOUZA, B.S.P.; GIOTTO, E.; PEREIRA, R.S. Lógica Fuzzy e Zoneamento ambiental da Bacia do Arroio Grande. In: SIMPÓSIO BRASILEIRO DE SENSORIAMENTO REMOTO, 12, 2005, Goiânia. Anais...Goiânia: INPE, 2005, p. 2355-2362

SAATY, T.L. Decision making with the analytic hierarchy process. International Journal of Services Sciences, v. 1, $n$. 1, p. 83-98, 2008.

SPÖRL, C. \& ROSS, J.L.S. Análise comparativa da fragilidade ambiental com aplicação de três modelos. GEOUSP: Espaço e Tempo, n. 15, p. 39-49, 2004.

STOLTON, S.; DUDLEY, N.; RANDALL, J. Natural Security: Protected areas and hazard mitigation. Gland: WWF and Equilibrium, 130 p., 2008.

TRICART, J. Ecodinâmica. Rio de Janeiro: IBGE/SUPREN, 31 p., 1977.

WISCHMEIER, W.H. \& SMITH, D.D. Predicting rainfall erosion losses - a guide to conservation planning. Washington, DC: US Department of Agriculture, 67 p., 1978.

ZOU, T. \& YOSHINO, K. Environmental vulnerability evaluation using a spatial principal components approach in the Daxing'anling region, China. Ecological Indicators, v. 78, p. 405-415, 2017.

ZUQUETTE, L.V. Mapeamento geotécnico preliminar na região de São Carlos. São Carlos, 1981. Dissertação (Mestrado em Geotecnia) Escola de Engenharia de São Carlos, Universidade de São Paulo. 